\title{
Design of Mobile Communication System for Emergency Services
}

https://doi.org/10.3991/ijim.v14i13.14623

\author{
Hussein Tuama Hazim, Hasanain Abbas Hasan Al-Behadili ${ }^{(凶)}$, \\ Thaar A. Kareem, Mays Kareem Jabbar \\ University of Misan, Amara, Iraq \\ dr-hasanain@uomisan.edu.iq
}

\begin{abstract}
Telecommunication technology serves several fields in the world. One of the most significant fields is the emergency services to provide a fast connection between the case, the vehicle and emergency treatment office. This paper is a part of a long-term project to design a reliable communication system service to be used for emergency services of a specific city. The hardware devices of this system are intended to work within an mm waves frequency. In the current research, as a starting point, an exhaustive study accomplished to pave the way to the main goal of the project. The system uses OFDM technology to improve the performance of the system. Other requirements for error correction are also included in the model such as convolutional, hamming coding and interleaving. The system development is supported by a Matlab interface software to simulate the job of an IoT real-time network covering both vehicles and the control centres.
\end{abstract}

Keywords - Internet of Things, Codec, Orthogonal Frequency Division Multiplexing, Modelling.

\section{Introduction}

Nowadays, telecommunication technologies have a predominant impact on the human's life. From mobile phones, smart TV's to the transportation system, communication is in demand for most of the sectors. Ambulance, firefighting and police have significant importance in providing health and safety for the people. For such services, time is the major parameter in improving the mentioned services. Ambulance, for example, need to reach the patient and make an initial diagnosis then to deliver the patient and during these stages, there is a need for best communication with the hospitals. Nowadays, communication devices used in vehicles are used to do a simple job which aims to provide a medical (or any other emergency) services. However, there is a demand to send and receive different data types not only voice but also written data, images and even videos. The status of such technology is through using call using GSM, 3G and in some countries via 4G. Designing more advanced systems can play an important role in addressing the problem of speed up the treatment of cases (patient, criminal chasing or firefighting). In this paper, initial thoughts of designing a system that uses a radio 
system for a city's emergency services are proposed. The long-term aims of the project are to invest the outcomes of such a study to use IoT in the communication system to deal with the mentioned problem.

\section{Previous Studies}

There are relatively several modern historical studies in the area of utilisation of telecommunication technologies in the medical, security and control of disasters areas. The aim behind using such technology is basically to save lives with less complexity and consumed time. Fire alarms and other similar detector tools were the early devices used for emergency. But, the modern industrial revolution devices like GPS, smartphones make a difference in the state of art of communication services. With the huge growth of population, there is a need for more advanced methods to deals with the services that engaged with their life. However, the fast development in telecommunication helps in enhancing the services in general and in the fields mentioned above in particular.

The academic literature on employing information technology in emergency services has revealed the emergence of several contrasting themes. Meissner et al., [1] were one of the interesting researches in this filed which discusses the management of disasters using information system and communication. El-Masri et al., [2] developed medical service based on advanced techniques such as mobile web technology which contributes to enhancing hand over of clinical services. In comprehensive literature of employing information technology in emergency services, Lachner and Hellwagner [3] give an overview of requirements of such services and tries to propose a prototype of emergency services based on communication technology. Management of emergency events is not only finite by the traditional method described previously. An example is studied by Pohl et. al., [4] has dealt with detection of emergency using two of most well-known social sites e.g. YouTube and Flicker, and this is in addition to Twitter in Pohl et al., [5]. A recent study by Shittu1 et. al., [6] dealt with discussing situations to manage the cases of communication failures in the response of organisation with emergencies. The ITU report [7] provides much information which explains the requirements, developments and other issues for relief disaster and protection of the public. With particular importance, the use of Internet of Things (IoT) in emergency applications has emerged recently and it has become an interesting topic. Study in [8] studied the application of IoT technology in the remedy of health emergency which focuses on injuries in road traffic. The study increases the knowledge in this field since they use genomic data in collecting data from patients rather than the traditional method of using Wireless Sensor nodes and wireless body area network which was employed partly. The use of IoT revealed a huge difference in the state of art of communications and since several research went to utilise this technology, it would be beneficial to enhance the knowledge in the field of emergency services. 


\section{Methods and Results}

Dealing with emergency situations, the time is very important to rescue. Figure 1 shows a simple algorithm of how such events managed.

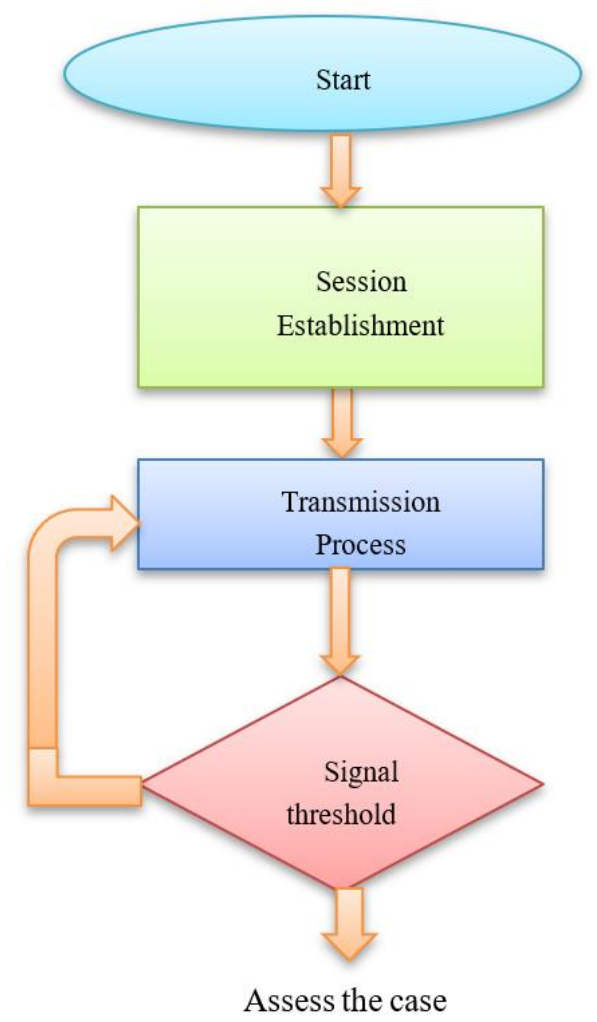

Fig. 1. Simple algorithm to communicate with mobile service.

If an event has been detected, a session establishment to communicate with the mobile service through a networking protocol as will be discussed later. Then, a transmission process performed using a system given in Figure 2. However, there is be a signal threshold to assess the quality of it, if it is not above the threshold level a notification sent back to enhance the quality and send it again. Finally, the case be assessed to decide at what level of urgency.

From the point of the relevance of this research, digital files that used in media (e.g. images, videos and voices) need in different occasions in the system processing to be compressed and/or decompressed to transmit(receive) the information easily. This is normally performed using a well-known software (or device) called a codec. 


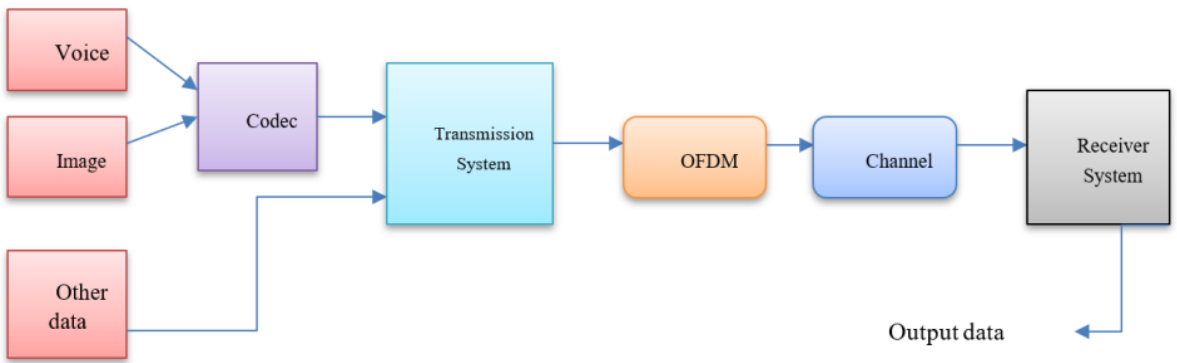

Fig. 2. Systems Framework

The codec employed here for processing of different data types that mentioned in dealing with the emergency callings and messages. The use of codec is very necessary to reduce the effect of noise. There are several types of codecs listed in [9] such as Voice G.711 and G.723, G.729 and GSM-AMR. However, it is not restricted to which type that be utilised but it should use Full-Duplex communication. To use Full-Duplex in transmission, the handshaking protocol is used Selective ARQ (this is used in case of sending the data) and Three-way handshaking (this is for to an efficient connection insurance between the two points). In addition to voice data, image data can be sent and received and it has been decided to use images with JEPG extension. JEPG is compatible for systems that used in emergency, the picture size may be changed to be of considerable size if the control centre (hospital, police station, etc.) need a high-quality picture to assess the (user, patent, criminal, etc.). Consequentially, picture with poor quality may be sent by the system. Then, this can be stored in a database, then it can be changed later.

Next, the signal fed into the transmission system which includes normal parts of a communication system such as convolutional encoder, Interleaver and modulation. Then, it followed by OFDM as the channel access method since the system is a mobile system and the system in this study intended to be used in the next mobile generation. This can also improve the system performance in view of data rate and a number of the user.

It is important to select the modulation type to be better in the purpose of the system. Among several types, the 64-QAM is compatible with this system since it has the smallest of the bit error rate. Moreover, according to [10], the use of Convolutional code would result in reduction of bit error which is good as compared with Hamming code, so it has been selected. Moreover, there was a need to use the interleaver. In [11] the use of interleaver with convolutional shows better performance than only using interleaver, and the interleaver here agrees with OFDM to face channel that has a severe fading. 


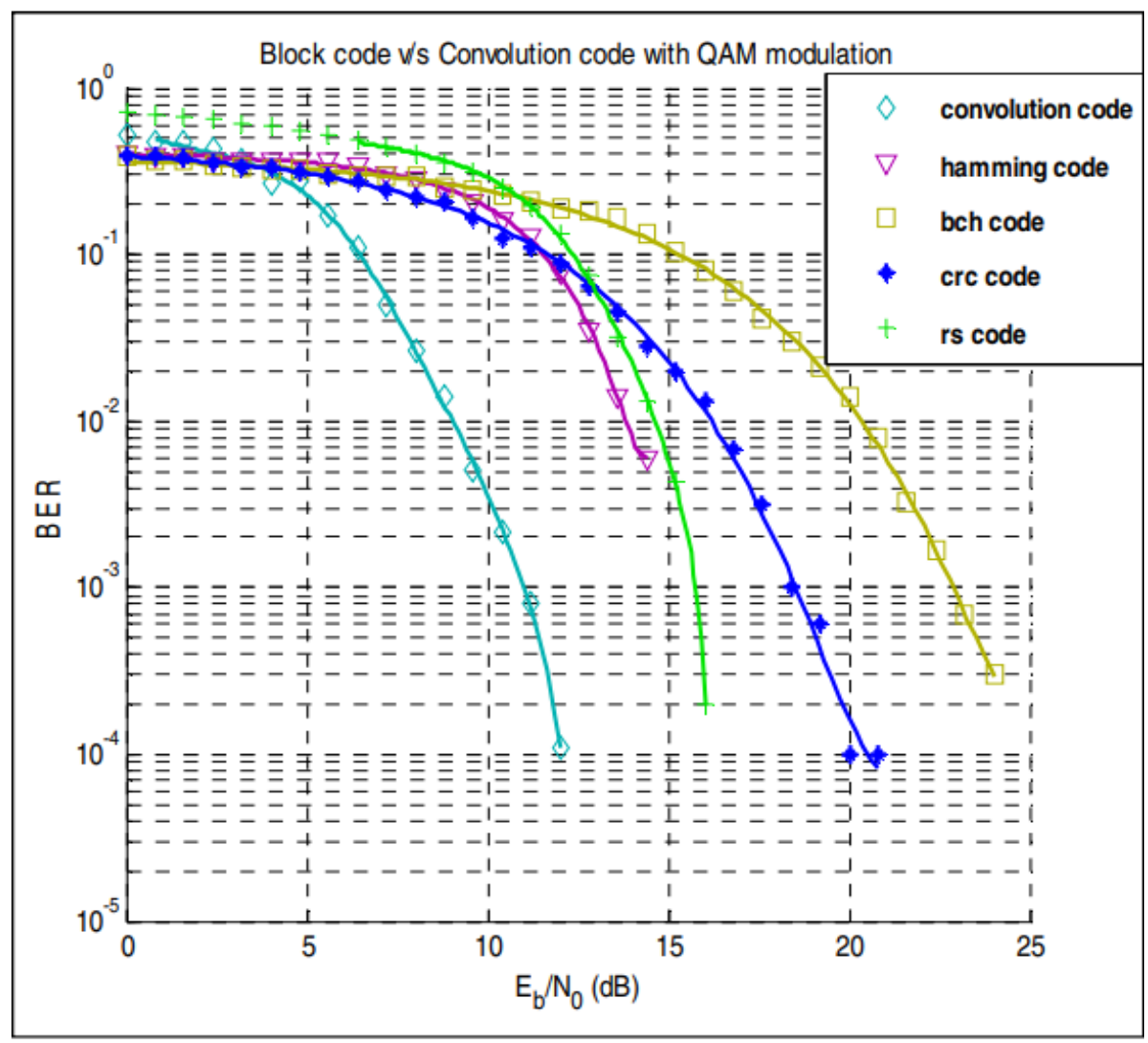

Fig. 3. The BER for different code types [10].

Since the system employed in this article is a band limited, the aim is to increase the capacity of the data to be transmitted as much as possible. However, it is known that the capacity of any communication channel is governed by the Shannon channel capacity formula which is given below:

$$
C_{p}=B \log _{2}(1+S / N)
$$

Where: $C_{p}$ is the channel capacity in bits per second

$\mathrm{B}$ is the bandwidth in $\mathrm{Hz}$

$\mathrm{S} / \mathrm{N}$ is the signal to noise ratio in $\mathrm{dB}$.

It was not possible to define a realistic value of bandwidth but in certain cases, bandwidth is limited to $100 \mathrm{kHz}$. However, there are various records of signal to noise ratio which results in producing different values of channel capacity which is given in Figure 3. Logically, the higher values of SNR leads to increment in channel capacity. 


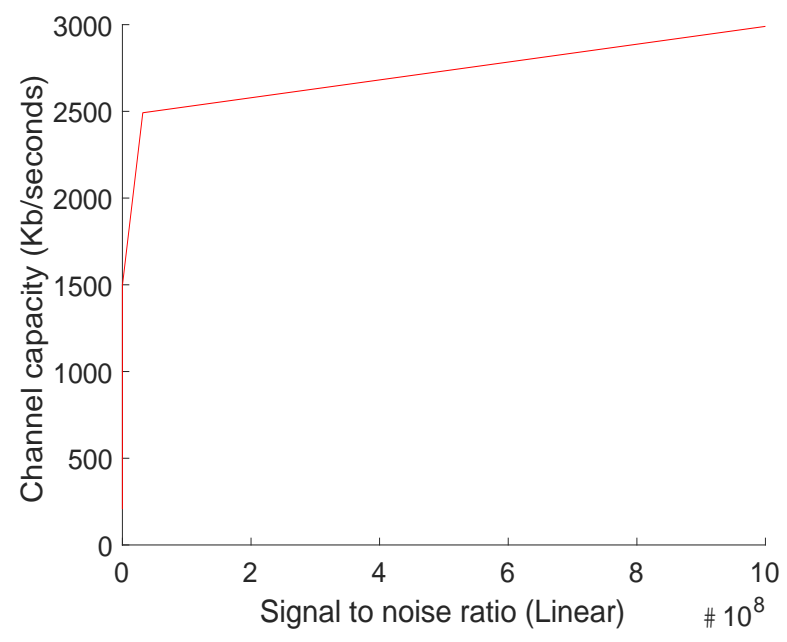

Fig. 4. Channel capacity for different signal to noise levels.

Two of the most common reasons for obtaining multi-signal to noise to noise ratio levels are due to the effect of Doppler shift and multipath fading. These are basically during emergency vehicle (i.e. police, ambulance, etc.) is moving. The Doppler frequency (D_f) is related to both the frequency of operation (f) and speed of the vehicle (v).

$$
D_{f}=f\left(\frac{v}{c}\right)
$$

c: is the speed of light.

Assuming (speed, frequency of operation, etc.)

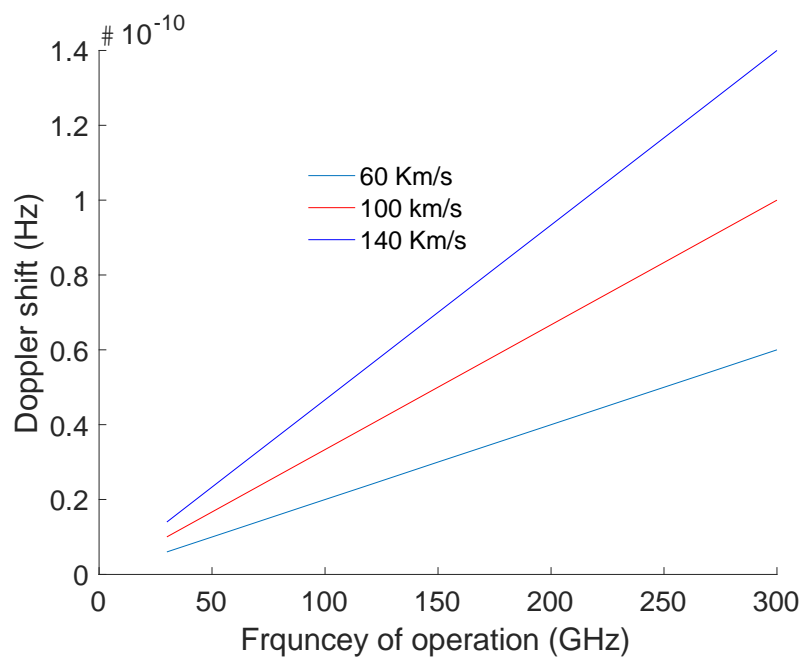

Fig. 5. Doppler with frequency of operation. 
Doppler normally results in the fading of the signal, using interleaver could reduce the effect of Doppler shift. Interleaver length $\left(L_{I}\right)$ has an inverse proportional to $D_{f}$

$$
L_{I}=\frac{C_{p}}{D_{f}}
$$

$C_{p}$ : is the channel capacity.

In order to assess the designed system, calculations of specific parameters were used. It has been assumed that signal power has different levels (this was based on the general fact that the signal will not take one steady-state value). Therefore, there will be several signal to noise ratio values which will then results in various records of channel capacity. Moreover, signal forms e.g. voice, image, other data occupy a graded amount of the total bandwidth. In other words, voices need double the signal bandwidth, which influences the channel capacity. If most of the time of the communication has a lower percentage of SNR, the capacity would be reduced greatly and vice versa. However, the person who declare the emergency action (sender) would not have enough information about the signal intensity of connection between the vehicle (here firemen, police car, ambulance) and control centre (fire station, police station, hospital) but he(she) could have received notice from the control centre. For example, for a connection of halfhour, total data capacity is given in Figure 6. In this Figure, there was an assumption that more than half of the time the SNR was not exceeded $15 \mathrm{~dB}$, and it is evident that this can affect the channel capacity as been mentioned.

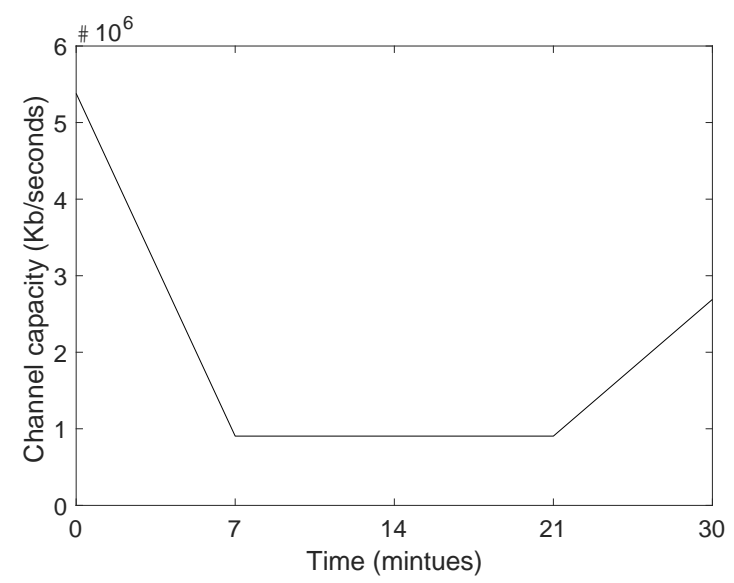

Fig. 6. Channel capacity distribution for half an hour.

It is important to remind that the implementation of codec can result in the quality (and quantity) of the transferred signal. For example, data has been sent using the two different codec types: ARM, G.711. With an assumption that the on-board data has a fixed value of about $300 \mathrm{bits} / \mathrm{sec}$, Figure 7 shows total bits of all data types for ten minutes. It is evident that using G.711 is better in view of the size of data that wished to be sent which is because G.771 codec has a lossless signal but with a fixed voice signal about $64 \mathrm{~Kb} / \mathrm{sec}$. 


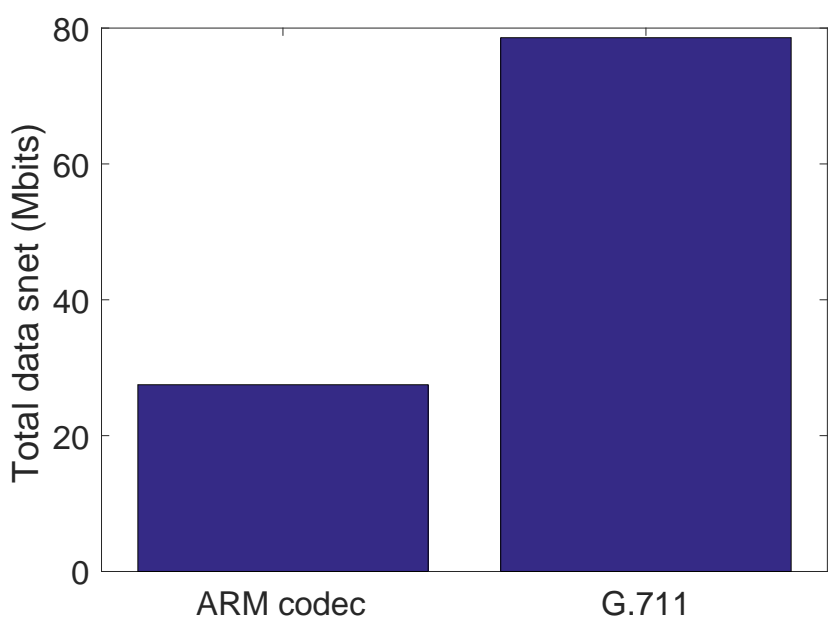

Fig. 7. Total data sent using two codec types.

Ongoing developments are to finish the hardware design and joint it with the Internet of Things (IoT) applications. The first work within our project is to give a vision of the communication system to be used for emergency safety services. The developments require using IOT infrastructure to support the speed of providing the service. In certain cases, there is a need to use WSN nodes to collect the information about the emergency situations, then to connect through the system described previously to the other points (e.g. hospital, police, etc.). Currently, the effort is to simulate the scenarios in the program related to the main project which is looking for more support by the mobile companies, fire services, police and hospital. It will start with Matlab Toolbox for IoT applications for event simulation. The reader may also refer to researches like in [12-15] to engage with mobile services understanding.

\section{Conclusion}

The role of the emergency service has crucial importance in saving lives of people. Improving the performance of such services can help in reducing the losses due to disasters, illness and fire. This study set out to understand the views and experiences of design parameters for a communication system for use by emergency service, namely; firefighting, police and ambulance. Information for this study came from various sources but they should be simultaneous. The present study has shed a contemporary light on the contentious issue of using the next generation in mobile emergency services. Although the current study is based on a small sample of results, it is open the way for the next step of the system development. A key strength of this paper was the feasibility of the design procedure by finding the best choices to use in the implementation of the system. More broadly, research is also needed to find the availability to introduce a mobile system based on IoT for an emergency. 


\section{Acknowledgement}

The authors would like to thank Dr David Siddle from the University of Leicester for giving them several advices particularly through suggesting the research key points and expected plans.

\section{References}

[1] Meissner, A., Thomas L., Thomas R., Thomas K., and Holger K. (2002). Design challenges for an integrated disaster management communication and information system. The First IEEE Workshop on Disaster Recovery Networks (DIREN 2002), 24: 1-7.

[2] El-Masri, S., and Basema S. (2012). An emergency system to improve ambulance dispatching, ambulance diversion and clinical handover communication-A proposed model. Journal of medical systems 36, 6: 3917-3923. https://doi.org/10.1007/s10916-012-9863-x

[3] Lachner, J., and Hermann H. (2008). Information and communication systems for mobile emergency response. In International United Information Systems Conference: 213-224. Springer, Berlin, Heidelberg.

[4] Pohl, D., Abdelhamid B., and Hermann H. (2012). Automatic sub-event detection in emergency management using social media. In Proceedings of the 21 st international conference on world wide web: 683-686. https://doi.org/10.1145/2187980.2188180

[5] Pohl, D., Abdelhamid B., and Hermann H. (2012). Supporting crisis management via subevent detection in social networks. In 2012 IEEE 21st International Workshop on Enabling Technologies: Infrastructure for Collaborative Enterprises: 373-378. IEEE. https://doi.org/ 10.1109/wetice. 2012.58

[6] Shittu, E., Geoffrey P., and Nancy M. (2018). Improving communication resilience for effective disaster relief operations. Environment Systems and Decisions 38,3: 379-397. https://doi.org/10.1007/s10669-018-9694-5

[7] Series, M. (2015). Radiocommunication objectives and requirements for public protection and disaster relief (PPDR). ITU, Switzerland, Tech. Rep. ITUR M: 2377-0.

[8] Edoh, T. (2019). Internet of things in emergency medical care and services. In Medical Internet of Things (m-IoT)-Enabling Technologies and Emerging Applications. Intech Open. https://doi.org/10.5772/intechopen.76974

[9] Hanzo, L., F. Somerville Clare F., and Jason W (2008). Voice and audio compression for wireless communications. John Wiley \& Sons.

[10] Kaur, J., and Shakti R. (2017). Performance evaluation of space codes using 16-QAM technique. In 2017 2nd International Conference on Telecommunication and Networks (TELNET) :1-6. IEEE. https://doi.org/10.1109/tel-net.2017.8343504

[11] Chen, Z., Wei Z., and Xi C. (2014). Convolutional interleaver used for OFDM-based cognitive radio systems in severely fading channel. In 2014 4th IEEE International Conference on Information Science and Technology:184-187. IEEE. https://doi.org/10.1109/icist.2014. $\underline{6920361}$

[12] AL-Behadili, H. A., Almaliki, M. N. S., and AlWane, S. K. A. (2019). A Ray Tracing Model for Wireless Communications. International Journal of Interactive Mobile Technologies (iJIM), 13(11), 245-251. https://doi.org/10.3991/ijim.v13i11.11730

[13] Kongsoontornkijkul, Kritika, Rath Pichyangkura, Pakpachong Vadhanasindhu, and Kanlaya Vanichbuncha. "Developing A Mobile Web for Innovative University Assessment System: 
Thailand Talent Mobility Programme." International Journal of Interactive Mobile Technologies (iJIM) 13, no. 11 (2019): 34-50. https://doi.org/10.3991/ijim.v13i11.10924

[14] Galustyan, Olga Vladimirovna, Alexander Pavlovich Smetannikov, Indira Grigoryevna Kolbaya, Galina Sergeevna Palchikova, Denis Vasilyevich Galigorov, and Olga Borisovna Mazkina. "Application of Mobile Technologies for the Formation of Analytical Competence of Future Specialists." International Journal of Interactive Mobile Technologies (iJIM)14, no. 02 (2020): 242-249. https://doi.org/10.3991/ijim.v14i02.11658

\section{$7 \quad$ Authors}

Mr. Hussein T. Hazim: His Major is Master of electronic telecommunication engineering from University of Pune, India.works as lecturer at Department of electrical engineering in university of Misan in Amarah, Misan city Iraq where he thought several courses. His current research interest includes wireless communication, artificial intelligent, deep learning, intelligent control systems and internet of things. E mail: hussein.tuama@uomisan.edu.iq

Dr. Hasanain Abbas Hasan Al-Behadili is a Lecturer at the Department of Electrical Engineering, Faculty of Engineering, Misan University, Iraq. He had a PhD in Communications Engineering from the University of Leicester, UK. He had with him 10 years' experience in teaching Electrical Engineering courses. Dr Al-Behadili has also experience in various programming languages and environments such as $\mathrm{C}, \mathrm{C}++$, Python programming, Matlab and many others. dr-hasanain@ uomisan.edu.iq.

Mr. Thaar A. Kareem is holding a Master's Degree in Communication Engineering by the University Eastern Mediterranean University (EMU), Cyprus. He is currently an assistant Lecturer at the Department of Electrical Engineering, University of Misan, Iraq.thaarkkareem@uomisan.edu.iq

Mrs. Mays Kareem Jabbar is holding a Master's Degree in Computer Enginnering by the Eastern Mediterranean University (EMU), Cyprus. She is currently a Lecturer at the Department of Civil Engineering, University of Misan, Iraq. m_mays85@uomisan.edu.iq

Article submitted 2020-04-04. Resubmitted 2020-05-13. Final acceptance 2020-05-24. Final version published as submitted by the authors. 